\title{
The Analysis of Selection and Influencing Factors of Vegetable Buying Channels of Community Residents in Beijing
}

\author{
Ping Li ${ }^{a}$, Guifen Lu ${ }^{b}$ \\ Beijing Vocational College of Agriculture, Beijing 102442, China \\ a nancy_yin2001@sina.com, b zbgborg@126.com
}

\begin{abstract}
This article carried out surveys on community residents in Beijing to obtain vegetable buying channels information. The influencing factors of buying decisions are analyzed to find the key factors. Taking this as a basis, some suggestions are proposed on the development mode of vegetable retail terminal in community. It is significant for solving the vegetable buying problems of convenience, price and safety.
\end{abstract}

Keywords: Beijing, community residents, vegetable buying channels, principal component analysis, buying decisions.

\section{Introduction}

The circulation of agricultural products has made a bridge between agricultural products and consumers, which plays an important role in agricultural products production, operation, sales and consumption. Because of its special environment, $90 \%$ of the vegetables in Beijing depend on the supply outside and the development of vegetable supply has been widely concerned. In the process of constructing a world-level city, Beijing must also have safe and sufficient agricultural products as a guarantee. Beijing has the characteristics of a dense population, rapidly developed economy, a high degree of internationalization, a higher per capita income. In this case, the level of demand of residents has changed accordingly. More and more people concern living environment and life health and they hope to buy products at ease and eat them at ease. However, the current market of agricultural products in Beijing is limited, and there are some flaws in the network covering, facilities and management level, which cannot meet consumers demand. What's worse, there are still some problems in organization structure, product source and operating mechanism in the market of agricultural products in Beijing, constraining it in agricultural products' source, supply, sale and market price. How to make residents eat both cheap and safe vegetables is an urgent problem to solve. This article carried out surveys on community residents in Beijing to obtain vegetable buying channels information. The influencing factors of buying decisions are analyzed to find the key factors. Taking this as a basis, some suggestions are proposed on the development mode of vegetable retail terminal in community. It is significant for solving the vegetable buying problems of convenience, price and safety.

\section{Survey Design}

This article conducts a field survey on resident's vegetable buying channels, obtaining the consumption information by the questionnaire. The respondents are mainly selected from community residents in Xicheng District, Xuanwu District and Chongwen District. Each district surveys 10 communities and surveys 25 communities totally. The questionnaire mainly includes three parts: basic information, buying channels and influencing factors. In the investigation of influencing factors, the scoring system is used to show the importance of each. The outline of the questionnaire is shown in Table 1.

750 questionnaires are sent out, and 688 are recovered, with a recovery rate of $91.73 \%$. After the unqualified data are deleted, the number of valid questionnaires is 675 , with an effective rate of $90.13 \%$. 
Table 1 . The outline of the questionnaire

\begin{tabular}{|c|c|c|c|c|c|}
\hline \multicolumn{2}{|c|}{ The 1st part } & \multicolumn{2}{|r|}{ The 2nd part } & \multicolumn{2}{|c|}{ The 3rd part } \\
\hline \multirow{3}{*}{$\begin{array}{c}\text { basic } \\
\text { information }\end{array}$} & $\begin{array}{c}\text { sex and } \\
\text { age }\end{array}$ & \multirow{3}{*}{$\begin{array}{l}\text { Buying } \\
\text { channels }\end{array}$} & choices of & \multirow{3}{*}{$\begin{array}{l}\text { influencing } \\
\text { factors of } \\
\text { channels } \\
\text { decisions }\end{array}$} & \multirow{2}{*}{$\begin{array}{c}\text { Degree of } \\
\text { satisfaction }\end{array}$} \\
\hline & $\begin{array}{l}\text { highest } \\
\text { education }\end{array}$ & & channels & & \\
\hline & $\begin{array}{l}\text { living } \\
\text { location } \\
\& \text { income }\end{array}$ & & $\begin{array}{c}\text { farmer's } \\
\text { market,supermarket,vegetable } \\
\text { shops in community, roadside } \\
\text { market, greengrocer's shop } \\
\text { facilitating people }\end{array}$ & & $\begin{array}{c}\text { factors of } \\
\text { agricultural } \\
\text { products, retail } \\
\text { terminal and } \\
\text { social culture }\end{array}$ \\
\hline
\end{tabular}

\section{Residents Vegetable Buying Channels}

After sorting out questionnaires data, we find the main channels of buying vegetables for residents in Beijing: farmer's markets, supermarkets, vegetable shops in community, roadside markets and mobile greengrocer's shops facilitating people. Mobile greengrocer's shop facilitating people is the mode of mobile vegetable cart like Xinfadi market. According to the survey result, vegetable shops in community hold a large proportion of $38.1 \%$. Residents choose community vegetable shops to buy vegetable because of its convenience and freshness. Supermarkets and farmer's markets are next to community vegetable shops, with a proportion of $28.2 \%$ and $30.6 \%$ respectively. The consumers choosing roadside markets account for $3.1 \%$. About $6 \%$ of consumers express high concern and recognition to the mobile greengrocer's shops facilitating people mode.

\section{Analysis of Buying Decisions Influencing Factors}

\subsection{Index Selection}

The software SAS9.0 is used to obtain more real and comprehensive data. The factor coefficient of some indexes is under 0.4, which has less influence on the result and can be wiped off. After the removing, eighteen indexes left are shown in Table 2.

Table 2. Design and Screening on Index

\begin{tabular}{|c|c|c|c|}
\hline The 1st level index & code & The 2nd level index & $\begin{array}{l}\text { Screening } \\
\text { results }\end{array}$ \\
\hline \multirow{5}{*}{$\begin{array}{l}\text { agricultural } \\
\text { products factors }\end{array}$} & A1 & freshness of products & $\mathrm{V}$ \\
\hline & A2 & safety of products & V \\
\hline & A3 & trophism of products & V \\
\hline & A4 & beauty of products & $\mathrm{V}$ \\
\hline & A5 & popularity of products & $\mathrm{V}$ \\
\hline \multirow{5}{*}{$\begin{array}{l}\text { social culture } \\
\text { factors }\end{array}$} & B1 & buying model of reference group & $\mathrm{V}$ \\
\hline & B2 & overall safety of agricultural products in society & $\mathrm{V}$ \\
\hline & B3 & consumption concept of agricultural products in the region & V \\
\hline & B4 & family member's consumption concept of agricultural products & $\mathrm{V}$ \\
\hline & B5 & overall safety of agricultural products in society & $\mathrm{V}$ \\
\hline \multirow{4}{*}{$\begin{array}{l}\text { retail terminal } \\
\text { factors }\end{array}$} & $\mathrm{C} 1$ & hygienic nature of the environment & $\mathrm{V}$ \\
\hline & $\mathrm{C} 2$ & price of products & $\mathrm{v}$ \\
\hline & $\mathrm{C} 3$ & convenience of buying & V \\
\hline & $\mathrm{C} 4$ & $\begin{array}{l}\text { terminal service quality,level of } \\
\text { standardization,packing,logistics and so on }\end{array}$ & $\mathrm{V}$ \\
\hline \multirow{4}{*}{ consumers factors } & D1 & $\operatorname{sex}$ & $\mathrm{X}$ \\
\hline & $\mathrm{D} 2$ & age & v \\
\hline & D3 & family monthly income & v \\
\hline & D4 & education & $\mathrm{X}$ \\
\hline
\end{tabular}




\subsection{Principal Component Analysis}

The analysis of principal component on the data adopts the software of SAS9.0. The combination between the eigenvalue criterion and the contribution rate of factor cumulative variance has a more accurate effect on accurately extracting the main components number. Therefore, this article takes the approach. The first step is to extract the principal components whose eigenvalues are greater than or equal to 1 , which are the initial factors. The second step, the number of these factors needs to meet the variance cumulative contribution rate of more than $80 \%$. The data obtained from the survey is calculated by SAS9.0, and the contribution rate is $84.16 \%$, which is greater than $80 \%$. That means these data can explain the original variables well. The principal component analysis method is used to calculate the factor loading matrix, but in order to differentiate the coefficient of the loading matrix to $0-1$, the variance of the initial factor loading matrix is rotated most, and the factor loading matrix after rotation is shown in Table 3.

The meaning of each factor and the quantitative relationship of the main indexes can be shown by the factor-loading matrix after rotation. Table 3 shows that there are four public factors. The first public factor is mainly concentrated on the five aspects of B1-B5, and the scoring weight of each index is more than 0.628 . This public factor is the social and cultural influencing factor. The second public factor is mainly concentrated on four aspects of $\mathrm{C} 1, \mathrm{C} 2, \mathrm{C} 3$, and $\mathrm{C} 4$ and the index weight is above 0.728 . This public factor is the retail terminal influencing factor. The contribution of the third public factor in four aspects of A1-A4 is relatively prominent, and this public factor is the productinfluencing factor. The fourth public factor is more prominent in two aspects, D2 and D3. This public factor is the age and family monthly income factor.

Table 3. Factor Loading Matrix After Rotation

\begin{tabular}{|c|c|c|c|c|c|c|}
\hline \multirow{2}{*}{$\begin{array}{l}\text { Sequence } \\
\text { number }\end{array}$} & \multirow{2}{*}{ Index } & \multicolumn{4}{|c|}{ Component } & \multirow{2}{*}{ Factor } \\
\hline & & 1 & 2 & 3 & 4 & \\
\hline B4 & family members'consumption concept & 0.772 & & & & \\
\hline B1 & buying ways of reference group & 0.755 & & & & \\
\hline B5 & $\begin{array}{c}\text { overall health of agricultural products in } \\
\text { society }\end{array}$ & 0.671 & & & & 0.869 \\
\hline B2 & $\begin{array}{c}\text { overall safety of agricultural products in } \\
\text { society }\end{array}$ & 0.642 & & & & \\
\hline B3 & consumption concept in the region & 0.628 & & & & \\
\hline $\mathrm{C} 1$ & hygienic nature of the environment & & 0.869 & & & \\
\hline $\mathrm{C} 3$ & convenience of buying & & 0.831 & & & 0973 \\
\hline $\mathrm{C} 2$ & price of products & & 0.816 & & & בות. \\
\hline $\mathrm{C} 4$ & terminal service quality & & 0.728 & & & \\
\hline A4 & beauty of products & & & 0.798 & & \\
\hline A3 & trophism of products & & & 0.781 & & \\
\hline A2 & safety of products & & & 0.761 & & 0.878 \\
\hline A1 & freshness of products & & & 0.691 & & \\
\hline A5 & popularity of products & & & 0.636 & & \\
\hline D2 & age & & & & 0.704 & 0.847 \\
\hline D3 & family monthly income & & & & 0.687 & \\
\hline
\end{tabular}

\subsection{Analysis Results}

(1) Age and income: The impact of age and income on the choice of vegetable buying channels is obvious. Due to the differences in background and ideas of times, the older consumers tend to go to the farmers' market, while the young people go to the supermarket more. Young residents with higher income pay more attention to shopping environment and quality, so most of them choose to go to the supermarket to buy the agricultural products.

(2) Agricultural products factors: According to Table 3, consumers pay more attention to agricultural products in the factors such as freshness, safety, nutritional value, brand and so on. Therefore, the vegetable retail terminal in community should pay enough attention to the freshness 
and safety of products, and continue to improve the logistics system based on unified procurement and unified distribution, speeding up the arrival speed and guaranteeing the quality to attract more consumers.

(3) Social factors: According to Table 3, consumers' selection of buying channels is obviously influenced by family members' consumption concepts to agricultural products, habits and customs, social perceptions to the safety of agricultural products. In recent years, as the development of economy and the popularization of online buying fresh products, many consumers begin to change shopping habits. It is also necessary for community vegetable retail terminal to change traditional ways or add new methods, such as placing orders online, picking up goods offline to provide more convenience to customers and keep pace with times.

(4) Retail terminal factors: According to Table 3, the factors such as the quantity of agricultural products, the convenience of transportation, and the shopping environment have also received the attention from consumers. With the improvement of people's living standard, people also begin to lay emphasis on the diversity of products and the traffic convenience. They also increase the demand for the shopping environment. Therefore, community vegetable retail terminal should pay attention to the comprehensiveness and collocation of categories, and try to meet the diverse needs of consumers.

\section{Conclusion}

With the improvement of living standard, residents have growing demands on the quality and safety of vegetables and the convenience of buying in addition to the price. Current buying channels and services cannot meet the needs of consumers and the circulation mode and management mode of vegetables need to be improved urgently. Community orientation is a mainstream trend. However, it is difficult to guarantee the quality of the community vegetable shops under current circulation mode, and supermarket buying is not convenient enough. Therefore, a new mode of community vegetable distribution is urgently needed to realize the direct docking of the production and marketing, shortening the circulation link to reduce the price and guarantee the quality. We can meet diversified needs through unified operation, unified procurement, unified distribution and the integration of online and offline. Community vegetable retail terminal can check and control the source, transportation, sales and other aspects of the product to ensure product quality and safety. Therefore, it can compete with other retail terminals.

\section{References}

[1]. Zhao Xiaofei, Tian Ye. "Research on the Innovation of Circulation Channel Model of China's Agricultural Products" [J]. Journal of Business Economics,2009, (2):16-22.

[2]. Zhang Guihua, Zeng Fusheng. "Influencing Factors and Countermeasures of Consumers' buying Decisions in Supermarket Chains of Agricultural Products" [J]. Collected Essays on Finance and Economics,2014, (2):85-89.

[3]. Wu Ying. "Research on the Cost and Profit Deconstruction of Different Types of Retail Terminals" [D]. Dalian: Dongbei University of Finance and Economics,2013.

[4]. Jiang Chengcheng. "The Construction of key Performance Indicator System for Logistics Enterprises Based on Principal Component analysis" [J]. Logistics Technology, 2014, (10): 174176.

[5]. Zhang Hongxia, A Yufa, Li Zhibo. "The Analysis of Influencing Factors and Marketing Strategies of Vegetable buying Behavior of Community Residents" [J]. The World of Survey and Research,2012, (8):20-23. 